\section{Scalp Needlestick Injury During Fine- Needle Aspiration Cytologic Evaluation Without Needle Manipulation: William Tell in the Laboratory, Not Quite}

T O THE EDI T O R-Galed-Placed et al. ${ }^{1}$ suggest using a modified method of fine-needle aspiration cytologic evaluation (FNAC) that eliminates manipulation of the contaminated needle to reduce the risk of occupational infection in healthcare personnel while retaining diagnostic accuracy. The modified method of FNAC eliminates excess needle manipulation by aspirating $2 \mathrm{~mL}$ of air into the syringe so that, subsequent to the procedure, the residual air can be used to empty the material in the needle. We describe a case of scalp injury in a cytopathologist who used this modified method of FNAC.

The cytopathologist aspirated $2 \mathrm{~mL}$ of air into a syringe before connecting a 25-gauge needle and performing FNAC on a thyroid nodule. She then proceeded to extract the cytologic material for examination. When she depressed the plunger, the high level of pressure inside the syringe (probably caused by a colloidal clot that was clogged the needle) caused the needle to shoot out. The needle hit the table where the cytopathologist was working and bounced, lodging in the scalp on the top of her head. The cytopathologist was referred to the emergency department and then to the infectious diseases department. The thyroid specimen had been obtained from a patient with no known bloodborne infections. After the exposure, the cytopathologist was followed up for 6 months, and results of virological and biochemical analyses remained normal.

FNAC has been performed in our hospital since 1993. More than 32,000 procedures have been performed to date, with only 4 occupational exposures reported $(0.01 \%$ of procedures).

Among healthcare workers, accidental needlestick injury is a major cause of occupational infection ${ }^{2}$ and is the most common type of parenteral contact, accounting for approximately two thirds of occupational exposures. ${ }^{3}$ More than $90 \%$ of needlestick injuries involve hands, but most anatomic sites have been affected. ${ }^{4}$ However, a review of data from the Italian SIROH (Studio Italiano Rischio Occupazionale da HIV Group) database on occupational exposures revealed that the head was involved in $11(0.03 \%)$ of 36,421 percutaneous injuries; 10 cases were due to nail scratches, and 1 case involved a dentist who hit his head on an instrument. ${ }^{3}$

Scalp injuries to fetuses during lidocaine injection associated with perineal infiltration for episiotomy have been reported, ${ }^{5}$ but to our knowledge, no needlestick injuries on the scalp of a healthcare worker have been described. Although we realize that this type of injury is extremely rare, it is a reminder that improbable injuries might lead to occupational infection in healthcare workers.

We agree that FNAC should be performed without manipulating the contaminated needle, but substantial attention must be given to other possible means of injury associated with use of this technique. In particular, during training, caution about careful application of pressure when expelling the tissue should be taught. In other words, to perform FNAC safely, you must use your head. The number of needlestick injuries can be reduced by use of improved technology, but at times we are "squeezing the balloon" and creating new, unrecognized risks even as we try to address old, recognized risks.

\section{Angelo Pan, MD; Liana Signorini, MD; Silvia Magri, MD;} Gabriella De Carli, MD

From the Istituto di Malattie Infettive e Tropicali, Spedali Civili, Università di Brescia, Brescia (A.P., L.S., S.M.), and the Istituto Nazionale per le Malattie Infettive Lazzaro Spallanzani, Rome (G.D.), Italy.

Address reprint requests to Angelo Pan, MD, Istituto di Malattie Infettive e Tropicali, Spedali Civili, Università degli Studi di Brescia, Piazzale Spedali Civili, 1, 20123 Brescia, Italy (ange.pan@tiscali.it).

Infect Control Hosp Epidemiol 2006; 27:996-996

(C) 2006 by The Society for Healthcare Epidemiology of America. All rights reserved. 0899-823X/2006/2709-0024\$15.00.

\section{RE F E R E N C E S}

1. Galed-Placed 1, Pertega-Diaz S, Pita-Fernandez S, Vazquez-Martul E. Fine needle aspiration cytology without needle manipulation to reduce the risk of occupational infection in healthcare personnel. Infect Control Hosp Epidemiol 2005; 26:336.

2. US Public Health Service. Updated US Public Health Service Guidelines for the Management of Occupational Exposures to HBV, HCV, and HIV and Recommendations for Postexposure Prophylaxis. MMWR Recomm Rep 2001; 50(RR-11):1-52.

3. Puro V, De Carli G, Petrosillo N, Ippolito G. Risk of exposure to bloodborne infection for Italian healthcare workers, by job category and work area. Studio Italiano Rischio Occupazionale da HIV Group. Infect Control Hosp Epidemiol 2001; 22:206-210.

4. Perry J, Parker G, Jagger J. EPINet report: 2002 percutaneous injury rates. Advances in Exposure Prevention 2004; 7:18-21.

5. Tjon a Ten WE. Lidocaine poisoning in a newborn infant following perineal infiltration for episiotomy [in Dutch]. Tijdschr Kindergeneeskd 1992; $60: 49-52$

\section{Compliance With Application Time for Surgical Hand Disinfection}

TO THE EDITOR-A formulation for disinfecting hands before surgery that requires a short, 1.5-minute application time was recently approved for marketing, on the basis of a 